\title{
Curriculum in Saudi Arabia
}

\author{
Ibrahim Alfarhan \\ Graduate Student, School of Education \\ Saint Louis University, St. Louis, United States \\ Ibrahim_uni@hotmail.com
}

Abstract: Curriculum in Saudi Arabia that had been used since the establishment of the country is still the same until now. Many practices are still being used on the same basis without being developed. Change was and still is the major issue in Saudi Arabia's education in general and more specifically in the curriculum. In this paper, the researcher will focus on the most common issues and highlights some solutions on the basis of philosophical views of famous philosophers.

Keywords: Curriculum, Understanding Students, Relating Content to Experience, School and Society, Natural Freedom.

\section{INTRODUCTION}

Following graduation from high school in his native Saudi Arabia, Nasser received a scholarship from the Saudi government to complete his bachelor's degree in the United States.

From the first day of class, Nasser encountered numerous issues alien to him. On that day, he was surprised by a very new educational experience - the classes in America are gender integrated, a policy unheard of in his culture. Initially, he was culturally unprepared for the experience as girls and boys outside the family unit, and neighbors are prohibited contact in Saudi Arabia.

Nasser once believed there is only one side of truth. There was no caring about other religions or cultures, therefore, living in the United States, with its variety of cultures, religion and beliefs was both confusing and enlightening for him. To accomplish his goals, he decided there were only two choices - he had to pick one of them. His first choice was isolating himself from the American community and living alone. But, if he did that, his language, understanding and social interchange with Americans would not improve; this would mean he would not reach his goals. The second choice was to accept people, connect with them and respect their beliefs. Unfortunately, Nasser is not the first person to face these issues when moving out of Saudi Arabia - most Saudi citizens do.

Looking back at the educational system in Saudi Arabia, it is easy to observe why Saudis have this issue. Schools in Saudi Arabia have to be reformed based on understanding of students of $21^{\text {st }}$ century, their needs and some practical educational philosophies and theories.

\section{Basis of Building the ARgument}

I feel there are two main points which could make the education process more practical and beneficial in an appropriate context. The first: I would like to highlight some of the insight from the article "Understanding Students" by David T. Hansen, Columbia University. The second being the great ideas of John Dewey's (1902) which will benefit more merging between curriculum content and students' experience. It would be helpful for 
educational systems in Saudi Arabia to relate all curriculum content to the students' understanding and needs. In fact, schools in Saudi Arabia might be able to use thoughts of David T. Hanson and Dewey with a few limitations.

\section{> “Understanding Students" By David T. Hansen}

In the beginning, "Understanding Students" leads to the activation of most of the goals and objectives of the educational process in general. Hansen mentioned that, "To understand students, the teacher seeks closeness not solely to the persons they are now, but also to the persons they are becoming and are capable of becoming" (Hansen, Winter 1999, pp.171-85). The school system in Saudi Arabia does not give much credence to this alien concept. The student's interests and objectives are of a secondary importance. But these were not priorities deserving of any degree of attention by school administrators. A learned philosophy which negated the students' interests and concerns for other personalities and cultures.

Most of students' personalities generally were a repeat or copy of those before him/her, whether they be parent, teacher or neighbor. Also, in the article, Hansen clarified the meaning of to be intellectually attentive in many contexts. First, he stated "To be intellectually attentive means considering the persons students may be becoming in the very next moment. It means being on the lookout for signs of students' anticipant interests, strength, and capacities." (Hansen, Winter 1999, pp. 171-85). Unfortunately, students in the Saudi school system were meant to be only receptive and rarely asked to react. A few teachers in the last two decades have started to give some importance to the students' interest and care more about what they are learning.

The new Saudi Minister of Education began to publish some of the new concepts that will help the students to be the essence of a key to the educational process and that their concerns be the fundamental basis for the process of study in the classroom. However, there is still a long way to go in providing a creative environment for students to exercise their interests. Also, teachers need a lot of training and development to get the required standards to understand the stages of transformation and transition of students during their educational process.

\section{$>$ "The Child and The Curriculum, Including the School and Society" $1902 \&$ "Experience and Education" (1938) By Dewey}

The next source I wish to cite for my argument are two articles by J. Dewey (1902) \& (1938). The first of which is in my opinion his great idea that schools must to "transform from old educational styles to a progressive educational styles." The main point Dewey was trying to pursue is schools need to be more realistic and relate to students' lives and experiences. Dewey mentioned that, "If one attempts to formulate the philosophy of education implicit in the practice of the new education, we may, I think discover certain common principles amid the variety of progressive schools now existing" (Dewey, 1938, p. 19). Therefore, if the schools in Saudi Arabia were to move from traditional education to the new educational theories, they will have to utilize two principal issues: 1. relating subjects to the children's experience, and 2. engaging and relating them into society.

The primary issue schools in Saudi Arabia have to confront is relating the subjects to the children's experience. The children's experience is the main thing which the schools have to consider before they build the curriculum and the method of teaching. To do that, schools have to understand children's life experiences in order to connect the content to children's experiences. The subjects should be fit for the child's age, and instead of memorization, children have to practice what they learn.

Up to this point, the role of schools in Saudi Arabia has been to convey knowledge and information to the children as laws and facts; however, this knowledge is irrelevant to the children's experiences, which makes it 
hard for children to engage with it. Thus, children will not be able absorb anything they have not faced in their lives. Instead of encouraging students to look at books with examples that they have not dealt with in their lives, teachers have to find examples that they can visualize in their lives. For example, if a geography teacher in third grade teaches students about nature, instead of bringing examples that are relevant to the children's environment, he might illustrate some examples that children deal with in their natural environment. In fact, children cannot relate to any content if they have no experience from their lives about it. As Dewey points out, "children live in a somewhat narrow world of personal contacts. Thus, subjects are hard to experience if the children are not exposed to them in their lives." (Dewey, 1902)

The subjects should also be age relative. Sometimes Saudi schools treat children as mature adults and the course content may be hard for them to understand if not are relative. An example of this is, children in elementary schools are taught driving laws, even though they will not be allowed to drive until they reach the age of 18 . The big question is how the children can absorb this lesson if they don't practice these laws. Hansen mentioned that "at the teaching's core is the commitment to serve students intellectual and moral growth." (Hansen, Winter 1999, pp. 171-85). This means we as teachers should be careful with the child's growth in both fields. Also, Dewey states that the "children cannot understand a subject matter without practicing; they need to learn actively." (Dewey, 1902) Schools must focus on what children need at their age; otherwise, they will leave school without getting enough knowledge and skills appropriate to their ages.

Lesson plans must incorporate both memorization of materials and application by rote (whenever possible). In Saudi Arabia, schools require children to memorize everything word by word without connecting it to their lives. For example, the schools encourage children to recite the Quran, which is Islam's holy book, without applying its subjects into the children's lives even though the Quran is applicable. Because Dewey states that "the schools have to subdivide each topic into studies and each study into lessons and each lesson into specific fact and formulae," I suggest schools divide the Quran into topics to let children absorb and practice them. "By letting the children proceed step by step, they will master each one of these separate parts, and at the end they will have covered all the material." (Dewey, 1902) Thus, if the schools do that with the Holy Quran, the students have a chance to understand its ideas and apply what they learn in their lives.

Another point of Hansen which supports acting with the students' interests is that not all students prefer the banking system in acquiring the new knowledge. Many students might prefer different instructional methods.

The second principle issue that schools need to consider when changing their educational theories is the importance of relating education to society. Because time and society are changing, people have different problems. Today, communities are not only home and neighborhood, the global world is also their community. Additionally, people around the world openly communicate and benefit from each other. Therefore, instead of living in past generations, schools in Saudi Arabia must be progressive and receptive to society's current needs. If the schools relate their educational content to the larger society, they will teach children how to solve their present problems, how to apply what they learn, and how to engage in a new community.

By relating education to society, schools will teach children how to solve their present problems. What is happening now in schools does not do that. For instance, the schools are teaching children how to feed the camels, which some children have never seen in real life. It would be more useful if the schools taught children how to preserve public parks and the benefits stopping destructive activities in them. That means schools will not be lagging behind society because they are changed from a traditional education to a "New Education" that makes the schools less isolated. "Thus, the schools will evolve in light of larger change in society; therefore, the schools will be able to connect this "New Education" with the general march of events." (Dewey, 1902) 
Children should be able to apply what they learn in schools. Dewey points out that when children come to the classroom, they are given a large amount of ideas and activities, but they do not apply them outside of the classroom. Therefore, how do the children receive any benefits unless they engage in what they are learning? For example, in the Alfegh section, which is under the religious field, the schools teach children that, "if you have 40 camels, you have to give poor people one sheep in order to be charitable." However, children in this country do not deal with camels or sheep, so how can they apply this idea? Instead, the schools can change this topic to monetary, which we use today; the schools can teach students that "If you have $\$ 40$, you have to give poor people $\$ 1$." That is easier for students to absorb and practice. I think it is important for Saudi schools to do what Dewey suggests: "the schools have to make connections between schools and business life."

The schools should teach children how to engage in new communities beyond their friends and families in their neighborhoods. In fact, schools have to prepare children for real life because having something to offer their community.

"We must conceive of them in their social significance, as types of the processes by which society keeps itself going, as agencies for bringing home to the child some of the primal necessity of community life, and as ways in which these needs have been met by the growing insight and ingenuity of man; in short, as instrumentalities through which the school itself shall be made a genuine form of active community life, instead of a place set apart in which to learn lessons." (Dewey, 1902, p. 14)

However, as I said in the beginning, the children's community is changing and the children are transforming from what they are now to what they will be. The teachers should adapt to it and become more than they were to grow the educational system. So too, the schools must teach children how to engage in a new community safely and to live with accepting others' ideas and thoughts. For example, many children are familiar with Facebook and Twitter, so I think schools should teach children how to safely use these technologies to make good friends around the world. Most students in Saudi Arabia do not know how to use new technology for their benefit; for example, they do not know how to shop or market online, or understand how to research progress in various fields of science around world by using the ERIC, and other databases. Schools must teach all these skills, but unfortunately, this is not happening: they are still living in the past generation.

Even though there are great ideas the Saudi Arabian educational system can benefit from and find useful, there are limitations to Dewey thoughts. Creating critical and thoughtful minds are the most important issues that countries in the Middle East are trying to fight for. In these countries, including Saudi Arabia, many people with critical minds may one day cause a cultural revolution with a positive outcome for all. Unfortunately, some Dewey's ideas, such as natural freedom, cannot be applied in this environment - they must wait.

Natural freedom is the basic need that human has to be given. Dewey mentioned that

"The only freedom that is of enduring importance is freedom if intelligence, that is to say, freedom of observation and judgment exercised in behalf of purposes that are intrinsically" (Dewy, 1938, p 61).

Unfortunately, schools are the place where students learn and say what they want, but students are still forbidden to talk about anything that is against the political hierarchy. The question here, how can teachers modify their teaching if students do not see what they have? Not only students, but also teachers are not allowed to talk about any political issues or even bring anything from outside of the curricula. In addition, in Saudi Arabia, the government annually purchases a national curriculum for all grades in all cities, so the whole country is given the same curricula without looking at the students' needs, experiences or interests. They do that in order to put all citizens in the same box, so students learn what the government wants, not what they need. 


\section{CONCLUSION}

In conclusion, Hansen, in his article, stated the importance of understanding students and how this would positively lead to a better learning experience. Understanding students will benefit mostly their intellectual and moral growth. Also, the great philosopher, Dewey, said "It is often well in considering educational problems to get a start by temporarily ignoring the school and thinking of other human situations" (Dewy, 1938, p53).

The school system in Saudi Arabia should care about children's experiences as well as interest and connect their education to society. If they do all these things, they will be preparing our children for the future. I recommend people who are working on school systems in Saudi Arabia build the school systems on philosophical theory and other countries' experiences, such as the United States and Germany.

\section{REFERENCES}

Hansen, D. Previously published in Journal of curriculum and Supervision 14 (2) (Winter 1999), pp. 171-85. Reproduced by permission of ASCD (Association for Supervision and Curriculum Department), Alexandrea

Dewey, J. (1902). The child and the curriculum, including the school and society. New York: Cosimo, Inc.

Dewey, J. (1938). Experience and Education. New York: Simon and Schuster.

Citation: Ibrahim Alfarhan, "Curriculum in Saudi Arabia"American Research Journal of Humanities and Social Sciences, Volume 2, 2016; pp:1-5

Copyright (c) 2016 Ibrahim Alfarhan, This is an open access article distributed under the Creative Commons Attribution License, which permits unrestricted use, distribution, and reproduction in any medium, provided the original work is properly cited. 